\title{
CONTEÚDO CIANOGÊNICO EM PROGÊNIES DE MANDIOCA ORIGINADAS DO CRUZAMENTO DE VARIEDADES MANSAS E BRAVAS ${ }^{(1)}$
}

\author{
TERESA LOSADA VALLE ${ }^{(2)}$; CÁSSIA REGINA LIMONTA CARVALHO ${ }^{(2)}$; \\ MARIA TERESA BARALDI RAMOS(2); GILDA SANTOS MÜHLEN ${ }^{(4)}$; OMAR VIEIRA VILLELA $^{(3)}$
}

\begin{abstract}
RESUMO
As variedades de mandioca (Manihot esculenta Crantz ssp esculenta) são classificadas pela taxonomia popular em bravas e mansas. As bravas têm sabor amargo, contêm alto teor de glicosídeos cianogênicos (superior a $100 \mathrm{mg}$ de equivalente $\mathrm{HCN} / \mathrm{kg}$ de polpa fresca de raiz) e são consumidas após serem processadas na forma de farinha, fécula e outros produtos. As mansas ou doces não têm sabor amargo, contêm baixo teor de glicosídeos cianogênicos, são consumidas com ou sem qualquer processamento, principalmente por meio de preparados domésticos simples. Neste trabalho, foram feitos cruzamentos para verificar o perfil cianogênico das progênies segregantes visando utilizar variedades bravas no melhoramento de mandiocas mansas. Duas variedades mansas (IAC 289-70 e IAC 576-70) e uma brava (SRT-1330 Xingu) foram polinizadas com uma variedade mansa (SRT-797 Ouro do Vale). Dos cruzamentos entre variedades mansas, 85,7\% dos genótipos apresentaram teores abaixo de $100 \mathrm{mg}$ eq. HCN/kg de polpa fresca de raiz. Do cruzamento entre as variedades mansa e a brava, apenas 31,3\% dos genótipos mostraram teores abaixo desse valor. A média das progênies foi muito próxima à média dos parentais. Em todos os cruzamentos, a maior freqüência de genótipos esteve na classe entre 50 e $100 \mathrm{mg}$ eq. HCN/kg de polpa fresca de raiz, mesmo no cruzamento entre brava e mansa. Em todos os cruzamentos apareceram segregantes transgressivos para maior e menor potencial cianogênico em relação a qualquer parental. $\mathrm{O}$ tipo de segregação observada indica ser a cianogênese um caráter com herança quantitativa que, embora tenha algum grau de influência ambiental, torna possível a seleção de indivíduos com maior ou menor teor cianogênico devido à alta herdabilidade oriunda de ampla variabilidade genotípica. Assim, variedades bravas podem surgir como recombinantes de variedades mansas, sendo também possível selecionar variedades com baixo teor cianogênico em cruzamentos de mandiocas mansas com mandiocas bravas.
\end{abstract}

Palavras-chave: ácido cianídrico, mandioca brava, mandioca mansa, melhoramento de mandioca de mesa.

\section{ABSTRACT \\ CYANIDE ACID CONTENT IN PROGENIES FROM CROSSES OF BITTER AND SWEET CASSAVA CULTIVARS}

Cassava varieties are popularly separated by taste as bitter or sweet cultivars. Roots of bitter cultivars have a high HCN content (over $100 \mathrm{mg} \mathrm{HCN}$ equivalent/ $\mathrm{kg}$ fresh roots) and are consumed only after processing, as flour, starch and other products. Sweet cultivars have low HCN content and can be consumed without any kind of processing. With the purpose of studing the possibility of using bitter varieties in the breeding of sweet cassava varieties, crosses were made between the different types of varieties to verify the cyanogenic profile of the segregating progenies. Two sweet varieties (IAC 289-70, IAC 576-70) and a bitter variety (SRT-1330 Xingu) were pollinated by a sweet variety (SRT-797 Ouro do Vale). Crosses

( $\left.{ }^{1}\right)$ Recebido para publicação em 22 de abril de 2003 e aceito em 4 de maio de 2004.

$\left(^{2}\right)$ Instituto Agronômico (IAC) - Caixa Postal 28, 13001-970 Campinas (SP), Brasil. E-mail: teresalv@iac.sp.gov.br; climonta@iac.sp.gov.br

$\left({ }^{3}\right)$ Pólo Regional de Desenvolvimento Tecnológico dos Agronegócios do Vale do Paraíba, Caixa Postal 32, 12400-000 Pindamonhangaba (SP).

$\left({ }^{4}\right)$ Bolsista de pós-doutorado da FAPESP, atualmente na Universidade Federal de Rondônia, campus de Rolim de Moura. 
between sweet cultivars yielded progenies with $85.7 \%$ of individuals with a HCN content below $100 \mathrm{mg}$ $\mathrm{HCN}$ equivalent $/ \mathrm{kg}$ fresh roots, while only $31.3 \%$ of the individuals from crosses between sweet and bitter varieties were under this value. The average HCN content of the progenies was very similar to the average of parents. In all crosses most of individuals showed values between 50 and $100 \mathrm{mg} \mathrm{HCN}$ equivalent $/ \mathrm{kg}$ fresh roots, even those derivated from the cross between sweet and bitter varieties. All crosses yielded transgressive segregants, with HCN content superior or inferior to either parent. The observed data show that the HCN content is a quantitative characteristic and that there is genetic variability allowing selections for high or low HCN content. Bitter cultivars may arise from crosses between sweet cultivars and sweet cultivars may be selected from crosses between sweet and bitter cultivars.

Key words: breeding, HCN content, sweet cassava, bitter cassava, sweet cassava breeding.

\section{INTRODUÇÃO}

A mandioca é uma espécie domesticada pelas populações pré-colombianas nas terras quentes da América. Devido à ampla adaptabilidade às condições ambientais e à capacidade produtiva, tornou-se alimento básico para muitas populações indígenas e complementar para outras (BROCHADO, 1977). Atualmente, é uma das principais fontes alimentícias para as populações dos países tropicais e importante matériaprima para a extração de amido.

Desde as culturas pré-colombianas até os dias atuais, a taxonomia popular, utilizando como critério a toxicidade e palatabilidade das raízes, classifica as variedades de mandioca em dois grupos: mansas ou doces e bravas ou amargas. De maneira bastante subjetiva, as variedades bravas têm sabor amargo e as doces não, são levemente adocicadas. O sabor amargo está associado ao potencial cianogênico, ou seja, à capacidade da liberação de ácido cianídrico (HCN), substância altamente tóxica (Pereira e Pinto, 1962; PeREIRA et al., 1965 e outros). Evidências revelam que o sabor amargo é perceptível a partir de $100 \mathrm{mg}$ eq. $\mathrm{HCN} / \mathrm{kg}$ de polpa das raízes (Dufour, 1988; LoRENZI et al.,1993). Não há entre os grupos qualquer característica morfológica da planta que permita distingui-los.

A diferença mais concreta entre variedades bravas e mansas encontra-se no modo de consumo. As bravas são utilizadas para produzir farinha, extrair amido e outros produtos, mas somente são consumidas após algum tipo de processamento industrial com efeito destoxificante. Variedades mansas são mais versáteis, podem ser destinadas ao processamento tal qual as variedades bravas, e também consumidas após preparos mais simples como cozidas, fritas ou assadas.

Até o início do século 20, na América, as variedades bravas e mansas seguiam um padrão de distribuição geográfica definido. Algumas tribos indígenas cultivavam somente mandiocas bravas, outras apenas mandiocas mansas e um terceiro grupo, utilizavam-se de variedades bravas e mansas (Nordenskiöld, apud Renvoize, 1972; BROCHADO, 1977).
As evidências citadas indicam ser possível a existência de duas populações, uma de variedades mansas e outra de variedades bravas. Estudos mais recentes com marcadores moleculares reforçam essa possibilidade, separando grupos de variedades bravas e mansas (MüHLEN et al., 2001).

Atualmente, em regiões do Centro-Sul do Brasil, há cultivo intensivo em grandes áreas, exclusivamente para fins comerciais. Próximo aos grandes centros urbanos, mandioca mansa (chamada de mesa) é cultivada em sistemas de produção diferenciados do cultivo de mandioca para as indústrias de farinha e amido. A produção de mandioca de mesa é uma atividade agrícola bastante expressiva e destinada somente à comercialização in natura e indústria de congelados. Variedades de mesa, além de bom desempenho agrícola, devem possuir qualidades sensoriais típicas e baixo potencial cianogênico para que não tenham sabor amargo e ofereçam riscos de intoxicação aos consumidores.

O objetivo deste trabalho foi avaliar a possibilidade de se utilizarem mandiocas bravas no melhoramento de mandioca de mesa no que tange à segregação do potencial cianogênico, visto que genótipos com alto potencial cianogênico não podem ser selecionados para variedades de mesa.

\section{MATERIAL E MÉTODOS}

As variedades IAC 576-70 (mansa), IAC 28970 (mansa) e SRT 1330-Xingu (brava) foram cruzadas com a variedade SRT 797-Ouro do Vale (mansa). As progênies e os parentais foram avaliados no campo em linhas de cinco plantas por genótipo, cultivados no Pólo Regional de Desenvolvimento Tecnológico dos Agronegócios do Vale do Paraíba, DDD/APTA, em Pindamonhangaba (SP). Para os genótipos segregantes não ocorreram repetições e, para os parentais, houve de quatro a oito repetições. Avaliaram-se, no mínimo, 32 genótipos de cada cruzamento. Aos doze meses, foi feita a colheita e de cada linha foram retiradas, aleatoriamente, no mínimo, sete raízes e enviadas ao 
laboratório para análise do teor dos glicosídeos cianogênicos (HCN). As amostras foram armazenadas dentro de sacos plásticos sob refrigeração até o momento da análise. Com a finalidade de avaliar perdas dos compostos cianogênicos durante o período de armazenagem das raízes, conjuntamente com as raízes coletadas, foram analisadas, periodicamente, amostras de uma variedade padrão (STR 1310 - Pioneira). Verificou-se que não houve perdas durante o período de armazenagem. Para a análise do teor de glicosídeos cianogênicos foram retirados três cilindros de aproximadamente $4 \mathrm{~cm}$, da parte inicial, mediana e distal de cada uma das raízes. Os cilindros foram descascados, triturados e homogeneizados. Duas subamostras de 50 g foram retiradas, quantificando-se o teor de glicosídeos cianogênicos, segundo o método argentimétrico descrito pela AOAC (WiLliams, 1990), mantendo-se as amostras em autólise durante 16 horas.

Os parâmetros genéticos foram estimados considerando-se: a) variância ambiental - diferenças entre repetições dos clones parentais; b) variância fenotípica - diferenças entre genótipos originados do mesmo cruzamento; c) variância genética - diferença entre a variância fenotípica e a média da variância ambiental estimada pelos dois parentais; e d) herdabilidade no sentido amplo (variância genética/variância ambiental).

\section{RESULTADOS E DISCUSSÃO}

\subsection{Variedades parentais}

As variedades utilizadas nos cruzamentos mostraram teor cianogênico dentro do esperado, de acordo com a taxonomia popular (Tabela 1). A variedade SRT 1330 - Xingu, de sabor pronunciadamente amargo, apresentou, em média, 379,1 mg eq. HCN/kg de polpa fresca de raiz. Nas variedades identificadas como mansas e sem sabor amargo (IAC 289-70, IAC 576-70 e SRT-797 Ouro do Vale), os teores de HCN foram, respectivamente, 56,3; 79,9 e 61,9 mg eq. HCN/ $\mathrm{kg}$ de polpa fresca de raiz, valores também observados em outros trabalhos com mandiocas mansas, ou seja, inferiores a $100 \mathrm{mg}$ eq. $\mathrm{HCN} / \mathrm{kg}$ de polpa fresca de raiz (Dufour, 1988; Lorenzi et al.,1993). A utilização dessas variedades mansas é indicativa de sua baixa cianogênese. As duas primeiras variedades são originadas do programa de melhoramento de mandioca de mesa do IAC. A IAC 576-70 é a mais cultivada no Estado de São Paulo para comércio in natura e indústria de congelados. A variedade SRT-797 Ouro do Vale é, desde a década de 60, amplamente cultivada em quintais da periferia urbana e áreas rurais, sendo bastante apreciada pelas suas excelentes qualidades culinárias e organolépticas.

\subsection{Cruzamentos}

Os genótipos recombinantes mostraram uma variação do potencial cianogênico bastante ampla, de 31,2 a $645,3 \mathrm{mg}$ eq. $\mathrm{HCN} / \mathrm{kg}$ de polpa fresca de raiz (Tabela 2). Nos cruzamentos envolvendo apenas variedades mansas, IAC $289-70 \times$ Ouro do Vale e IAC576-70 x Ouro do Vale, $84,2 \%$ e $87,2 \%$ dos genótipos, respectivamente, apresentaram potencial cianogênico inferior a $100 \mathrm{mg}$ eq. $\mathrm{HCN} / \mathrm{kg}$ de polpa fresca de raiz, ou seja, dentro do padrão de seleção para mandiocas de mesa. Nenhum genótipo ultrapassou a faixa de $150 \mathrm{mg}$ eq. $\mathrm{HCN} / \mathrm{kg}$ de polpa fresca de raiz. No cruzamento em que participou a variedade altamente tóxica ' $X i n g u$ ', $31,3 \%$ dos genótipos da progênie obtiveram potencial cianogênico inferior a $100 \mathrm{mg}$ eq. $\mathrm{HCN} / \mathrm{kg}$ de polpa fresca de raiz, portanto dentro da categoria de mandioca mansa, e $15 \%$ dos indivíduos tiveram mais de $400 \mathrm{mg}$ eq. $\mathrm{HCN} / \mathrm{kg}$ de polpa fresca de raiz, que são altamente tóxicos.

Tabela 1. Número de repetições, média, desvio-padrão e coeficiente de variação do teor de glicosídeos cianogênicos de variedades de mandioca utilizadas em cruzamentos

\begin{tabular}{lcccc}
\hline Parentais & Repetições & Média & Desvio-padrão & Coeficiente de variação \\
\hline & n. $^{\circ}$ & mg eq. HCN/kg de polpa fresca de raiz & $\%$ \\
IAC 289-70 & 4 & 56,3 & 5,7 & 10,1 \\
IAC 576-70 & 7 & 79,9 & 17,0 & 22,4 \\
SRT 1330 - Xingu & 4 & 379,1 & 65,1 & 17,2 \\
SRT 797 - Ouro do Vale & 8 & 61,9 & 13,4 & 21,7 \\
\hline
\end{tabular}


Tabela 2. Cruzamento, genótipos avaliados, média dos parentais, da progênie, amplitude do teor de glicosídeos cianogênicos e genótipos selecionáveis em cruzamentos de mandioca

\begin{tabular}{lccccc}
\hline Cruzamento & $\begin{array}{c}\text { genótipos } \\
\text { avaliados na } \\
\text { progênie }\end{array}$ & $\begin{array}{c}\text { Média } \\
\text { dos parentais }\end{array}$ & $\begin{array}{c}\text { Média } \\
\text { da progênie }\end{array}$ & Amplitude & $\begin{array}{c}\text { Genótipos } \\
\text { selecionaveis }^{(1)}\end{array}$ \\
\hline IAC 289-70 x SRT 797 - Ouro do Vale & 38 & mg eq. HCN/kg de polpa fresca de raiz & $\%$ \\
IAC 576-70 x SRT 797 - Ouro do Vale & 39 & 59,1 & 68,5 & $31,2-134,3$ & 84,2 \\
SRT1330-Xingu x SRT 797 - Ouro do Vale & 32 & 70,9 & 74,4 & $33,6-159,8$ & 87,2 \\
\hline
\end{tabular}

$\left({ }^{1}\right)$ Genótipos com teor cianogênico inferior a $100 \mathrm{mg}$ eq. $\mathrm{HCN} / \mathrm{kg}$ de polpa fresca de raiz.

O número de genótipos abaixo do nível crítico de cianogênese no cruzamento envolvendo a variedade Xingu, cerca de $31 \%$, viabiliza sua utilização no melhoramento de mandioca de mesa. No entanto, é necessário considerar-se que mandiocas bravas não sofreram pressão de seleção para consumo in natura e podem conter genes desfavoráveis para características peculiares em mandioca de mesa como paladar atípico e qualidades culinárias desfavoráveis. Genótipos com baixo teor de HCN também podem, em raríssimas exceções, apresentar sabor amargo porque essas características parecem não ter o mesmo controle genético, embora sejam altamente correlacionadas fenotipicamente nas variedades nativas (PEREIRA e PINTO, 1962; PEREIRA et al., 1965).

As maiores freqüências dos genótipos segregantes estão na classe entre 50 e $100 \mathrm{mg}$ eq. $\mathrm{HCN} / \mathrm{kg}$ de polpa fresca de raiz, mesmo no cruzamento em que participou a variedade Xingu (Figura 1). Esse tipo de segregação pode ser compreendida se considerarmos que a cianogênese é um processo metabólico secundário, ou seja, não essencial, que resulta na liberação do gás HCN para defesa da planta. A liberação desse gás depende fundamentalmente de uma complexa rota metabólica enzimática de síntese e transporte do substrato linamarina (sintetizado a partir da valina) e da atividade da enzima linamarase (B-glucosidase), e ainda, do contato entre ambos (McMaHon et al., 1995). Assim, para que uma variedade de mandioca tenha alto potencial cianogênico é necessário que todos os genes envolvidos no processo cianogênico estejam em perfeito funcionamento. Perturbações em qualquer passo do controle genético do sistema contribuiriam para a diminuição do potencial cianogênico. $\mathrm{O}$ acúmulo dessas perturbações explica a maior freqüência de genótipos com baixo teor cianogênico.
Segregantes transgressivos apareceram nos três cruzamentos. Aqueles que envolveram variedades mansas, IAC 289-70 x Ouro do Vale e IAC576-70 x Ouro do Vale, produziram, respectivamente, $21 \%$ e $18 \%$ dos indivíduos com teor de HCN inferior a 50 $\mathrm{mg}$ eq. $\mathrm{HCN} / \mathrm{kg}$ de polpa fresca de raiz (Figura 1), enquanto os parentais estiveram na faixa de 56,3 a 79,9 $\mathrm{mg}$ eq. $\mathrm{HCN} / \mathrm{kg}$ de polpa fresca de raiz (Tabela 1 ). Mesmo o cruzamento entre variedades brava e mansa (Xingu x Ouro do Vale) obteve 3\% dos indivíduos da progênie na classe de menor teor cianogênico (Figura 1). Segregantes transgressivos para baixo potencial cianogênico também foram encontrados por IgLESIAS et al. (2002) em cruzamentos de variedades bravas com mansas.

Cerca de $16 \%$ e $10 \%$ dos genótipos dos cruzamentos de variedades mansas atingiram níveis entre 100 e $150 \mathrm{mg}$ eq. $\mathrm{HCN} / \mathrm{kg}$ de polpa fresca de raiz e $3 \%$ atingiram a classe de 150 a $200 \mathrm{mg}$ eq. $\mathrm{HCN} / \mathrm{kg}$ de polpa fresca de raiz (Figura 1). Assim, é possível supor que, em regiões onde se cultivam variedades mansas para produção de fécula ou farinha, podem aparecer variedades bravas através de recombinação, como é o caso da 'Branca de Santa Catarina', uma variedade com alto teor de glicosídeos cianogênicos, que ocupou grandes áreas de cultivo no Estado de São Paulo.

As médias das progênies aproximaram-se das médias dos respectivos parentais nos três cruzamentos e surgiram indivíduos transgressivos aos parentais para maior e menor cianogênese (Tabela 2).

A variância genética foi duas a quatro vezes superior à variância ambiental nos cruzamentos entre variedades mansas e, quase dez vezes superior no cruzamento entre mansa e brava (Tabela 3 ). 


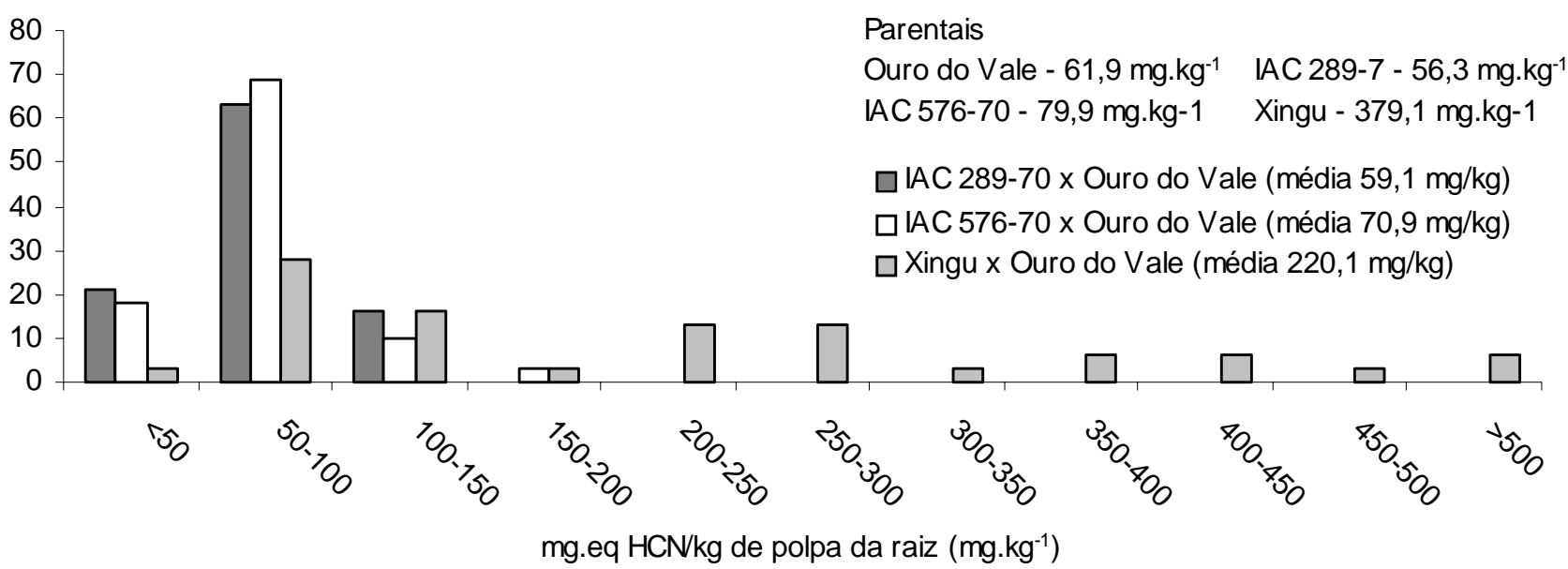

Figura 1. Distribuição de freqüência de genótipos em classes segundo o teor de glicosídeos cianogênicos em três cruzamentos de mandioca.

Tabela 3. Variâncias fenotípica, ambiental e genética e herdabilidade do teor de glicosídeos cianogênicos em cruzamentos de mandioca

\begin{tabular}{lcccc}
\hline Cruzamentos & $\begin{array}{c}\text { Variância } \\
\text { fenotípica }\end{array}$ & $\begin{array}{c}\text { Variância } \\
\text { ambiental }\end{array}$ & $\begin{array}{c}\text { Variância } \\
\text { genética }\end{array}$ & \begin{tabular}{c} 
Herdabilidade $^{(1)}$ \\
\hline IAC 289-70 x SRT 797 - Ouro do Vale
\end{tabular} \\
mg eq. HCN / kg de polpa fresca de raiz & $\%$ \\
IAC 576-70 x SRT 797 - Ouro do Vale & 565,02 & 106,47 & 458,55 & 81,2 \\
SRT1330-Xingu x SRT 797 - Ouro do Vale & 739,88 & 250,39 & 489,48 & 66,2 \\
\hline
\end{tabular}

( ${ }^{1}$ Herdabilidade no sentido amplo (variância genotípica / variância fenotípica).

Assim, o tipo de segregação observada indica ser a cianogênese um caráter com herança quantitativa. Embora tenha algum grau de influência ambiental, é possível selecionar indivíduos com maior ou menor teor cianogênico devido à alta herdabilidade oriunda de ampla variabilidade genotípica.

Nos cruzamentos envolvendo apenas as variedades mansas, os valores da herdabilidade mostraram que $66,2 \%$ e $81,2 \%$ da variabilidade foi causada por diferenças genéticas entre os indivíduos. No cruzamento em que participou a variedade Xingu, altamente tóxica, a variação genotípica foi responsável por $90,8 \%$ da variação total. Portanto, uma vez que a principal responsável pela variação do potencial cianogênico nas progênies é a constituição genética dos indivíduos, espera-se que processos seletivos simples, como a escolha dos parentais e a avaliação fenotípica, sejam eficientes para reduzir o teor de glicosídeos cianogênicos em populações segregantes.

\section{CONCLUSÕES}

1. O teor de glicosídeos cianogênicos não é impeditivo para a utilização de mandiocas bravas no melhoramento de mandiocas de mesa.

2. A segregação transgressiva do caráter permite o aparecimento de variedades mansas nos cruzamentos que participam mandiocas com alto potencial cianogênico.

3. Variedades bravas podem surgir do cruzamento de variedades mansas. 


\section{REFERÊNCIAS}

BROCHADO, J. P. Alimentação na floresta tropical. Porto Alegre: Universidade Federal do Rio Grande do Sul, 1977, 103p. (caderno n. 2)

DUFOUR, D. L. Cyanide content of cassava (Manihot esculenta, Euphorbiaceae) cultivars used by Tukanoan Indians in Northwest Amazonia. Economic Botany, v.42, n.2, p.255-266, 1988.

IGLESIAS, C.A.; SANCHEZ, T.; YEOH, H. Cyanogens and linamarase activities in storage roots of cassava plants from breeding programs. Journal of Food Composition and Analysis, v.15, n.4, p.379-387, 2002.

LORENZI, J.O.; RAMOS, M.T.B.; MONTEIRO, D.A.; VALLE, T.L.; GODOY JUNIOR, G. Teor de ácido cianídrico em variedades de mandioca cultivadas em quintais do Estado de São Paulo. Bragantia, Campinas, v.52, n., p.1-5, 1993.

MCMAHON, J. C.; WHITE, W. L. B.; SAYRE, T. Cyanogenesis in cassava (Manihot esculenta Crantz). Journal of Experimental Botany, v.46, n.288, p.731-741, 1995.
MÜHLEN, G. S.; COLOMBO, C. A.; VALLE, T. L. Mandioca brava e aipim: diferenciação genética. In: CONGRESSO BRASILEIRO DE MELHORAMENTO DE PLANTAS, 1., 2001, Goiânia. Anais... (resumo expandido) - CD-Rom

PEREIRA, A.S.; PINTO, M.G. Determinação da toxicidade da mandioca pelo paladar das raízes "in natura". Bragantia, Campinas, v.21, nota n.25, p.CXLV-CL, 1962.

PEREIRA, A.S.; NERY, J.P.; IGUE, T. Seleção de novos clones de mandioca para mesa, pela toxicidade e paladar de suas raízes "in natura". Bragantia, Campinas, v.24, nota n.10, p. LV-LVIII, 1965.

RENVOIZE, B.S. The area of origin of Manihot esculenta as a crop plant - a review of the evidence. Economic Botany, v.26, n.4, p.352-360, 1972.

WilLiAms, S. (Ed.). Hydrocyanic acid in beans, alkaline titration method. In: Official Methods of Analyses of the Association of Official Analytical Chemists. $15^{\text {th }}$ ed. Arlington: AOAC, 1990. p.1213. 